
SEPARATION IN BROADBAND OPEN ACCESS

Andres Hervas-Drane 
The Public-Private Sector Research Center is a Research Center based at IESE Business School. Its mission is to develop research that analyses the relationships between the private and public sectors primarily in the following areas: regulation and competition, innovation, regional economy and industrial politics and health economics.

Research results are disseminated through publications, conferences and colloquia. These activities are aimed to foster cooperation between the private sector and public administrations, as well as the exchange of ideas and initiatives.

The sponsors of the Public-Private Sector Research Center are the following:

- Accenture

- Ajuntament de Barcelona

- Departament d' Economia i Coneixement de la Generalitat de Catalunya

- Departament d' Empresa i Ocupació de la Generalitat de Catalunya

- Diputació de Barcelona

- Endesa

- Fundació AGBAR

- Institut Català de les Indústries Culturals

- Mediapro

- PricewaterhouseCoopers

- Sanofi Aventis

- ATM, FGC y TMB

The contents of this publication reflect the conclusions and findings of the individual authors, and not the opinions of the Center's sponsors. 


\title{
NON-COST-RAISING DISCRIMINATION: A RATIONALE FOR FUNCTIONAL SEPARATION IN BROADBAND OPEN ACCESS*
}

\author{
Andres Hervas-Drane ${ }^{1}$
}

\begin{abstract}
I present a vertical differentiation model to assess the quality-wise strategy of an incumbent telecommunications operator under open access regimes. I show that it is always profitable for an incumbent subject to wholesale regulation to degrade wholesale quality in a non-recoverable fashion. The findings are robust to the number of competitors and the price cap level, unlike those predicted by the cost-raising discrimination paradigm. I also show that functional separation, a structural remedy aimed to separate the incumbent's wholesale and retail operations, better aligns supply-side incentives with those of consumers. The analysis suggests that structural remedies exhibit good properties to implement open access regimes.
\end{abstract}

Keywords: Broadband Regulation, Open Access, Quality of Service, Discrimination

JEL Classification: D42, L12, L15, L22, L42, L96

* I am grateful to Francesc Trillas for generous advice and support throughout the development of this paper.

I thank Mark Armstrong, Tom Kiedrowski, Massimo Motta, Eli Noam, Pau Olivella, and Leonard Waverman for additional advice and suggestions. I also thank seminar participants at the Universitat Autònoma de Barcelona's Microeconomics brown bag and the Network Separation Conference at Columbia Business School. This research was largely conducted at the Universitat Autònoma de Barcelona and London Business School. Financial support from the FPU program of the Spanish Ministry of Education, grant EC02009-11307 of the Spanish Ministry of Science and Innovation, and the IESE Public-Private Sector Research Center are gratefully acknowledged.

\footnotetext{
${ }^{1}$ Universitat Pompeu Fabra and IESE Public-Private Sector Research Center (andres.hervas@upf.edu)
} 


\section{Introduction}

Open access policies are at the core of telecommunications regulation worldwide. In most advanced economies, incumbent operators are subject to regulation that attempts to ensure fair access to their network infrastructure, specifying under which conditions and prices they should provide access to competitors. ${ }^{1}$ If incumbents were free to unilaterally set the terms of access, in the absence of such open access requirements, broadband markets could largely remain foreclosed to competitors. The rationale for open access regulation is that entry barriers in the telecommunications sector are significant, due to the large costs required to duplicate network infrastructure. The goal of open access regimes is to reduce entry barriers and enable competition among several operators, thus increasing competition in the market with respect to the scenario in which only competitors capable of replicating each other's infrastructure could compete. ${ }^{2}$

In recent years, a new form of structural intervention known as functional separation has started to gain traction to implement open access regimes. Although open access policies define the terms of service under which access should be provided, proponents of functional separation argue that quality of service discrimination limits the effectiveness of such policies. Incumbents can engage in discrimination by exploiting their control of the infrastructure and harm competitors to their own benefit. Functional separation attempts to level the playing field for all operators by separating the management of the incumbent's infrastructure from her retail operations, sacrificing any benefits derived from the incumbent's vertical integration in the process. This separation attempts to curb the incumbent's incentives to engage in discrimination against entrants, and promotes competition based on retail and value-added services supplied over a common infrastructure. Pioneered in its current form by the United Kingdom in 2005, functional separation has since been adopted by several countries including Sweden, Italy, The Netherlands, New Zealand, and Australia, and is under consideration for adoption in several more. ${ }^{3}$

The economics literature has mostly analyzed the problem of discrimination under open access regimes applying the cost-rising discrimination paradigm, which assumes that reduced wholesale quality increases rivals' costs. That is, if a reduction in wholesale quality renders the product of rivals inferior to that of the incumbent, rival firms need to incur additional costs to match the incumbent's product. Under this approach, it has been shown that the incumbent's incentives to discriminate depend crucially on the number of competitors and the access price set by the regulator. These findings question the justification for structural intervention in the form of functional separation, and suggest that regulatory fine-tuning of wholesale requirements could achieve similar goals.

\footnotetext{
${ }^{1}$ A notable exception is the United States, which has historically favored infrastructure-based competition outside the period following the 1996 Telecommunications Act. See Katz [14] for a review of the policy implications of this bill, which gave impetus to open access regulation in other countries.

${ }^{2}$ Although this paper is concerned with the specific characteristics of the broadband sector, similar concepts apply to other industries based on network infrastructure such as the electricity and railway industries.

${ }^{3}$ See the Berkman report [9].
} 
This paper presents a stylized model that can explain why discrimination is a pervasive problem under open access regimes based on wholesale requirements, and why functional separation can solve it. The starting point for the analysis is the observation that discrimination over network infrastructure is generally of the non-cost-raising form, in the sense that it directly renders inferior the product of rivals over dimensions which they cannot offset by incurring additional costs. The link assumed in the cost-raising discrimination literature, namely that wholesale quality degradation raises rivals' costs, may not hold if rivals have no control over the input. This is due to the fact that incumbents engaging in discrimination largely control and service their infrastructure exclusively, an argument which I illustrate with evidence from the UK market.

The vertical differentiation model presented here explains the incumbent's incentives to engage in non-cost-raising discrimination under open access regimes, and why these incentives are robust to the number of competitors and the access price level. I show that this type of discrimination effectively reduces the degree of competition in the market, weakening competitors and reducing consumer welfare. I also show that functional separation eliminates the incentives to discriminate by rendering discrimination unprofitable. The analysis suggests that, as long as all operators interact on equal terms with the infrastructure unit, functional separation can better align the incentives that govern the bottleneck infrastructure with those of consumers.

This work is directly related to the extensive literature on cost-raising discrimination. The initial strand of this literature analyzed the problem under a Cournot framework, where downstream products are perfect substitutes and firms differ in their cost structures. Economides [8] finds that the incumbent has strong incentives to raise rivals' cost by engaging in cost-raising discrimination. Sibley and Weisman [22] and Weisman and Kang [25], however, find that a large number of downstream firms or a high access price can offset the incentives for cost-raising discrimination. Other contributions have considered Bertrand competition downstream, as in Beard, Kaserman and Mayo [3] and Mandy and Sappington [16], and find that incentives for cost-raising discrimination in this setting also depend on the access price and the intensity of downstream competition. ${ }^{4}$ A review of this literature is provided by Sappington [19] in a survey on regulating quality of service. Armstrong and Sappington [2] review the problem within the broader context of the theory of regulation.

To analyze non-cost-raising discrimination, and in contrast to the previous literature, I consider a pure vertical differentiation framework where consumers observe the quality of service supplied by operators when deciding to purchase broadband products. ${ }^{5}$ The main novelty of this approach

\footnotetext{
${ }^{4}$ Mandy and Sappington [16] also consider a form of non-cost-raising discrimination which they refer to as demand-reducing sabotage. This differs from the form of discrimination considered in this paper and is further discussed in Section 3.3.

${ }^{5}$ Consumer surveys confirm that quality of service plays an important role in broadband markets. A survey performed by the UK regulator, Ofcom, found that 'the highest level of [consumer] concern in the internet market continues to be about service issues, driven by concerns over slow connection speeds.' An independent survey by Broadbandchoices.co.uk found that 'more than a third of consumers rate connection reliability as the most important factor when it comes to broadband.' Although switching costs and network effects arguably play a relevant role
} 
is the fact that the incumbent controls the qualities supplied on the market, including (indirectly) those of competitors. The framework is based on those pioneered by Gabszewicz and Thisse [12] and later extended by Shaked and Sutton [21], the particular specification closer to Tirole [23]. I focus on the case where a discrete number of qualities are offered on the market and firms compete in prices after the quality setting stage. ${ }^{6}$ My analysis builds on the monopoly solution, which was first analyzed in a more general setting by Mussa and Rosen [17].

Several assumptions are made to simplify the basic model and analyze the incentives for noncost-raising discrimination. On the supply side, the incumbent's production technology is simplified to a zero cost structure, discrimination is costless, and gains derived from vertical integration are not considered. On the demand side, demand specification is linear and given by a uniform distribution of valuations for quality among consumers. I review these assumptions after completing the analysis of the basic model. The takeaway is that the findings are generally robust to the presence of cost structures and non-linear demands, as well as positive costs of discrimination and scope economies as long as they are not too high. Other implications of vertical integration economies present a more complex case, however, and are further discussed in the review.

\subsection{The case for functional separation in the UK}

The United Kingdom was the first country to introduce functional separation in its recent form with the establishment of Ofcom in 2005, a new telecommunications regulator with increased powers. ${ }^{7}$ To understand the process, it is useful to review the European regulatory context and the challenges faced by Ofcom. Most fixed broadband lines in the European Union are deployed over Digital Subscriber Line (DSL) technology. 8 This technology enables high-speed data transmission over copper telephone networks which are largely under the control of the incumbent operators, which were historically established as public monopolies. The EU implemented open access regimes in a 2002 directive that required incumbents to offer wholesale interconnection to their copper networks. With the implementation of this directive, broadband markets across the EU were reshaped by legal and technical battles between incumbents and entrants, with the incumbents' networks often at the center of the debate. While the outcome in each Member State varied depending on initial conditions and the engagement of local regulators, incumbents have sustained large market shares

in the market, neither appear to be as relevant to consumers as quality of service. See Ofcom's 'The Consumer Experience 2009. Telecoms, Internet and Digital Broadcasting,' December 2009, and Broadbandchoices.co.uk's 'Broadband connection reliability is most important,' September 2009.

${ }^{6}$ The case where firms choose quality ranges instead of discrete qualities has been analyzed by Champsaur and Rochet [6] in a setting with mixed vertical differentiation. Competition with firms choosing quantities rather than prices has been considered by Dixit [7] and Gal-Or [13] for the case of discrete qualities and quality ranges, respectively.

${ }^{7}$ See Ofcom's Strategic Review of Telecommunications, 2005.

${ }^{8}$ See the European Competitive Telecommunications Association (ECTA) Q3 2009 broadband scorecard. 
and higher retail prices than entrants. ${ }^{9}$

The local incumbent in the UK, British Telecom (BT), repeatedly failed to agree with entrants over the conditions for the implementation of the directive. BT resisted the implementation of an open access regime both by posing technical hurdles in the process, and later, as revealed by Ofcom, by discriminating against competitors. Ofcom required BT to start publishing key performance indicators in 2004, reporting performance separately for competing operators and its own retail arm in order to test for quality of service discrimination. The data reported here covers the end user access circuit, the last mile of the copper network owned and serviced exclusively by BT. Competitors purchasing wholesale service from BT depend on this stage of the network, so quality discrimination here affects them all. Figure 1 shows the percentage of orders not completed by customer confirmed date and the average time in hours to restore service on fault.

The data confirms that the average quality served to competing operators over BT's infrastructure was lower, suggesting that the incumbent selectively degraded wholesale service. ${ }^{10}$ This observation motivates the analysis of non-cost-raising discrimination presented in this paper. Note that, unlike assumed in the cost-raising discrimination literature, competitors cannot offset reduced wholesale quality by incurring additional costs as they have no access to BT's infrastructure. It is also worth noting that, despite operating in the presence of an engaged and powerful regulator, BT was able to successfully discriminate against its competitors. Monitoring for discrimination is challenging for regulators, since incumbents hold private information on their networks and engage in strategic disclosure. Thus the extent to which regulators can enforce non-discrimination clauses when the incumbent has incentives to breach them is called into question.

Moreover, there are several dimensions of quality of service beyond those reported above that could be subject to discrimination. The incumbent could delay network infrastructure investments that benefit entrants, deploy additional capacity selectively, or priorize data traffic routed over her network. For example, the incumbent could implement data traffic management schemes that priorize her own retail customers, or could priorize her own data applications and services over those of competitors. ${ }^{11}$ In all these scenarios, quality discrimination directly renders inferior the product of competitors with respect to the incumbent's, thereby reducing their potential market share and profitability.

\footnotetext{
${ }^{9}$ See the broadband retail price survey published by CMT, the Spanish telecommunications regulator, 'Comparativa internacional de ofertas comerciales de banda ancha en la Unión Europea,' December 2010.

${ }^{10} \mathrm{BT}$ argued that coordination difficulties with other operators affected the measures, such as the rearranging of dates for service previously confirmed with customers. It seems doubtful, however, that a date BT could not meet would be arranged. Similarly, average time to restore service includes delays due to other operators because BT's system 'cannot recognise parked time and therefore cannot account for it.' Nonetheless, parked time cannot be significant for maintenance work on infrastructure under BT's control.

${ }^{11}$ The discrimination of content in transit over data networks is a prominent element in the network neutrality debate. Rubinfeld and Singer [18] review the antitrust concerns of such a scenario within the context of the AOL and Time Warner merger in the US. To the extent that functional separation ensures that wholesale revenues depend only on connectivity, and not content, it precludes the incentives for such discrimination to arise. In fact, functional separation should be implemented as the separation of conduit and content.
} 


\section{Percentage of orders not completed by customer confirmed date}

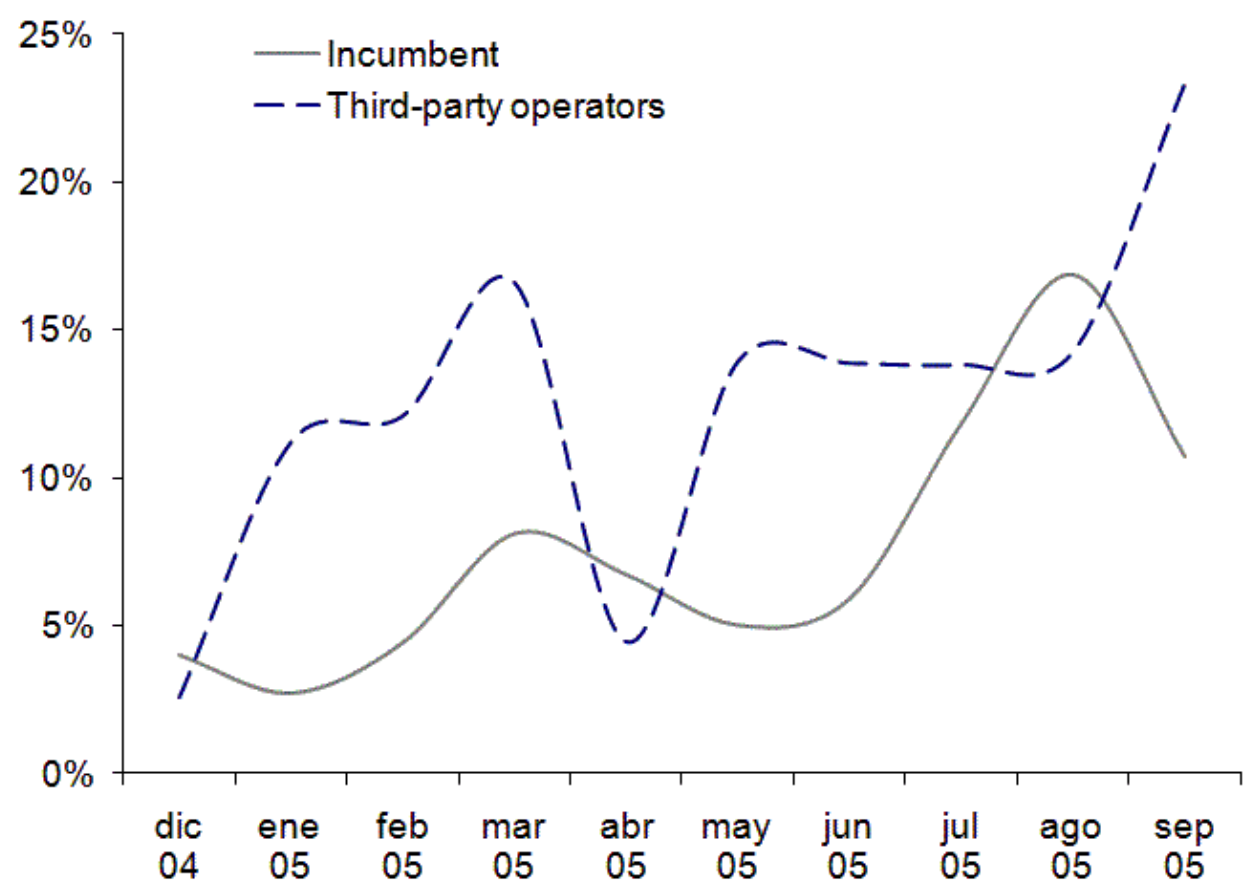

\section{Average time in hours to restore service on fault}

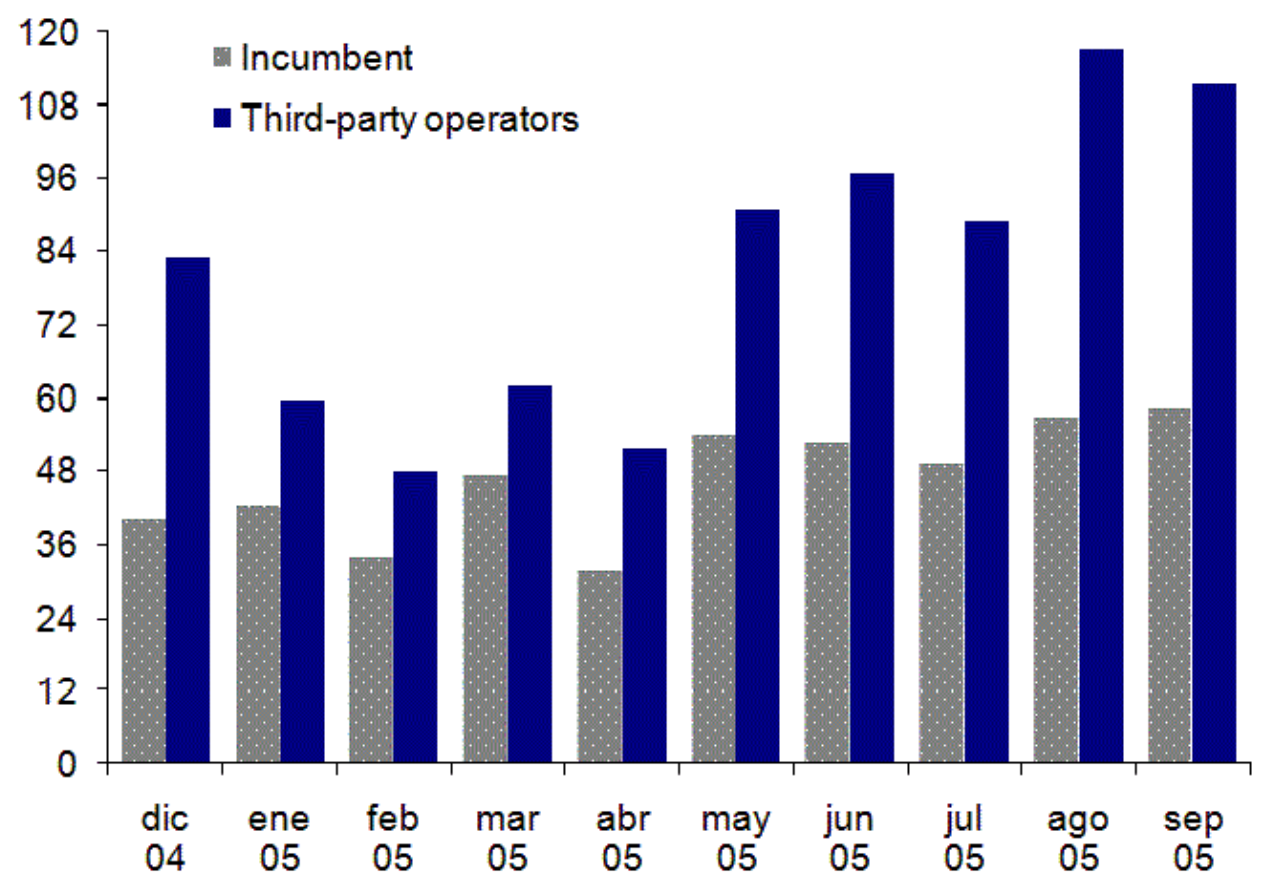

Figure 1: Percentage of orders not completed by customer confirmed date (top) and average time in hours to restore service since fault registration (bottom), both on the end user access circuit as published by the UK incumbent, British Telecom. Third-party operators is an average of the top ten providers by installed base excluding the incumbent. 
Ofcom implemented functional separation by forcing BT to create Openreach, an independent unit to manage its physical network and provide access to all telecommunications operators, including both the retail operations of BT itself and competing operators. In this process, the incumbent's infrastructure and its retail operations became two separate business units, dealing with each other at arm's length. Ofcom made two goals of functional separation explicit. The first was equivalence of input, implying that Openreach should supply inputs to all operators in the market under the same systems, conditions and timeframes. To this end, Openreach implemented a single and common interface to interact with all operators, and an Equality of Access board was established. A second goal was to ease monitoring of the functionally separated network by the regulator. Openreach set up a separate headquarters office from BT, and Ofcom designed performance bonuses and penalties for management and staff accordingly.

The remaining of the paper is organized as follows. The next section introduces a stylized vertical differentiation model to analyze non-cost-raising discrimination. Section 3 analyzes market outcomes under different regulatory frameworks. To simplify the exposition I first consider the benchmark case of an unregulated incumbent, next the case of functional separation, and then turn to wholesale regulation. Section 4 presents a welfare analysis of all market configurations. Section 5 discusses the implications of the simplifying assumptions present in the model and considers some extensions. Section 6 reviews the findings in the context of the broader regulatory debate and concludes.

\section{The model}

Consider a unit mass of consumers demanding broadband service. Consumers differ in their valuation of quality, and any consumer $j$ has a valuation $\theta_{j}$ pertaining to the uniform distribution $\theta \sim U\left[0, \theta^{+}\right]$. The consumer $\theta_{j}=0$ does not derive value from quality, and the consumer $\theta_{j}=\theta^{+}$ values quality the most.

Demand for broadband products in the downstream market will depend on both quality and price. The utility obtained by consumer $j$ from consuming product $i$ with quality $S_{i}$ and price $p_{i}$ is given by

$$
u_{j}\left(\theta_{j}\right)=\theta_{j} S_{i}-p_{i}
$$

and the utility obtained when consuming product $i$ will differ among consumers. If several products of different qualities are supplied on the market at the same price, all consumers prefer the product with the highest quality. Thus demand is characterized by consumer unanimity over product quality rankings, so this is a model of pure vertical differentiation. When different quality

products are supplied at different prices, however, consumers will generally differ on their utility maximizing choice. Consumers exhibit unit demand, and may purchase a single product or stay 
out of the market. The outside utility of not purchasing is normalized to zero. ${ }^{12}$

Broadband products are served over the incumbent's infrastructure, and feasible product qualities are defined by a compact space $S_{i} \in\left[0, S^{+}\right]$. So product qualities are bounded. The maximum feasible quality given the technical limitations of the infrastructure is captured by $S^{+}$. The lowest feasible quality is zero, low enough that no consumer derives value from the product. Throughout the analysis the incumbent may offer consumers any number of products at different quality and price points. Similarly, when operating under an open access regime, the incumbent (or the wholesale division managing the infrastructure in the case of functional separation) may serve any number of wholesale products at different quality and price points. The incumbent will be subject to a price cap $\bar{p}$ under open access, however, so wholesale products cannot be priced above $\bar{p}$.

I will refer to the incumbent's competitors as entrants. There are $n \geq 2$ entrants present in the market that demand wholesale access to the incumbent's infrastructure to offer broadband products. ${ }^{13}$ Under open access, consumers can choose from at least $n+1$ broadband products in the downstream market supplied by $n+1$ operators. The production technology exhibits fixed proportions, and each entrant requires one unit of upstream input from the incumbent to service a downstream customer. Due to the fact that product qualities are infrastructure dependent and the infrastructure is under the incumbent's control, entrants cannot improve upon the qualities supplied (nor incur additional costs to do so).

To focus on quality of service discrimination, I simplify the cost structure to the largest extent possible. Fixed costs, variable costs, and quality costs are assumed to be zero. It is costless for the incumbent to introduce any number of products and qualities, or to engage in discrimination by reducing the quality served to entrants. This assumption is useful to focus the exercise on the role of demand-side factors and the pricing interactions among firms, because it avoids complications arising from the production costs of different product varieties. Section 5 discusses the impact of richer cost structures in the model as well as the potential implications of vertical integration on the incumbent's costs.

The timing of the game is as follows:

\begin{tabular}{|c|c|c|c|}
\hline 10 & 20 & 30 & 40 \\
\hline $\begin{array}{l}\text { Quality } \\
\text { choices } \\
\text { (incumbent) }\end{array}$ & $\begin{array}{l}\text { Wholesale } \\
\text { pricing } \\
\text { (incumbent) }\end{array}$ & $\begin{array}{l}\text { Retail pricing } \\
\text { (incumbent } \\
\text { and entrants) }\end{array}$ & $\begin{array}{l}\text { Consumers } \\
\text { purchase }\end{array}$ \\
\hline
\end{tabular}

\footnotetext{
${ }^{12}$ This outside option and the fact that the consumer with the lowest valuation for quality $\theta_{j}=0$ does not value quality ensures the market will remain uncovered in equilibrium. Note that consumer $\theta_{j}=0$ would only purchase (out of indifference) at price zero, but $p_{i}=0$ will never be an optimal price for products that can sustain market shares at positive prices. This allows corner conditions for a covered market to be excluded from the analysis. Wauthy [24] first raised the point that market coverage in this family of models should be endogenous. Nonetheless, assuming $\theta^{-}=0$ enables the empirically relevant case to be formalized while reducing analytical complexity. I discuss alternative demand specifications in Section 5.

${ }^{13}$ The results are not affected by the exact number of entrants $n$ as long as $n>1$. This is due to the fact that the incumbent will benefit from inducing price competition among entrants. If there was a unique entrant in the market, the qualitative results on discrimination would hold but the entrant would be able to price above cost and extract positive profits.
} 
The first stage is the quality choice stage. The incumbent decides what product qualities to supply, both upstream (to entrants) and to downstream consumers (at retail). The second stage is the wholesale pricing stage, where the incumbent quotes upstream prices. Retail pricing decisions take place in the third stage, when all operators quote their downstream prices. In the fourth stage consumers observe qualities and prices and make their purchasing decisions. All games are solved by backwards induction. Whenever multiple payoff-equivalent equilibria arise, I focus on the solution that minimizes the number of qualities on the market.

\section{Equilibrium quality of service}

\subsection{Unregulated monopoly}

I start by considering an unregulated and vertically integrated incumbent. This case will serve as a benchmark to understand the impact of open access regulation on the market. The incumbent chooses retail qualities and prices in order to maximize total profits, and there are no open access requirements. The following lemma characterizes the solution.

Lemma 1. The monopoly solution is to offer a unique retail product of maximum quality. The market outcome is characterized by

$$
S_{r}^{*}=S^{+} \quad \text { and } \quad p_{r}^{*}=\frac{\theta^{+} S^{+}}{2}
$$

yielding profits

$$
\pi_{\text {monopoly }}^{*}=\frac{\theta^{+^{2}} S^{+}}{4}
$$

Proof. Mussa and Rosen [17].

The result follows from the more general analysis of Mussa and Rosen [17] for the case where production is costless and consumers' valuation for quality is uniformly distributed. It is useful for the exposition to restate the result here.

Consider the problem of an incumbent introducing $N$ retail products in the market. Denote product $i$ with price $p_{i}$ and quality $S_{i}$, and order products in decreasing quality sequence, $S_{1}>$ $S_{2}>\ldots>S_{N}$. This requires $p_{1}>p_{2}>\ldots>p_{N}$ for all products to be relevant, as otherwise some products are dominated by higher quality alternatives available at equal or lower prices. Consider a candidate equilibrium where all $N$ products face positive demand. Given the consumer utility function (1) the following must hold for consumers demanding the highest quality product:

$$
\theta_{j} S_{1}-p_{1} \geq 0 \quad \text { and } \quad \theta_{j} S_{1}-p_{1} \geq \theta_{j} S_{i}-p_{i} \text { for all } i \neq 1
$$


Hence consumers purchasing product 1 must be those that most value quality and exhibit high values of $\theta$. The additional conditions for those consumers that purchase the remaining products $i>1$ imply that consumers with lower values of $\theta$ will purchase products of lower quality. The incumbent's profit function can be written by identifying the consumers that are strictly indifferent between purchasing products of neighboring quality or indifferent between purchasing the lowest quality product and staying out of the market. Let $S=\left(S_{1}, \ldots, S_{N}\right)$ and $P=\left(p_{1}, \ldots, p_{N}\right)$ denote the vectors of qualities and prices, then

$$
\begin{gathered}
\pi_{\text {monopoly }}(S, P)=D_{1}(S, P) p_{1}+\ldots+D_{i}(S, P) p_{i}+\ldots+D_{N}(S, P) p_{N} \\
=\left(\theta^{+}-\frac{p_{1}-p_{2}}{S_{1}-S_{2}}\right) p_{1}+\ldots+\left(\frac{p_{i-1}-p_{i}}{S_{i-1}-S_{i}}-\frac{p_{i}-p_{i+1}}{S_{i}-S_{i+1}}\right) p_{i}+\ldots+\left(\frac{p_{N-1}-p_{N}}{S_{N-1}-S_{N}}-\frac{p_{N}}{S_{N}}\right) p_{N} .
\end{gathered}
$$

Solving the first order conditions of this expression with respect to prices obtains the optimal pricing strategy:

$$
p=\left\{\begin{array}{l}
p_{1}=p_{2}+\frac{\theta^{+}}{2}\left(S_{1}-S_{2}\right) \\
p_{i}=\frac{S_{i-1} p_{i+1}+S_{i}\left(p_{i-1}-p_{i+1}\right)-S_{i+1} p_{i-1}}{S_{i-1}-S_{i+1}} \text { for all } 1<i<N \\
p_{N}=p_{N-1} \frac{S_{N}}{S_{N-1}}
\end{array}\right.
$$

Solving this system of equations yields

$$
p_{i}^{*}=\frac{\theta^{+} S_{i}}{2}
$$

and the solution implies that $D_{i}\left(S, P^{*}\right)=0$ for all $i>1$ independently of $p_{1}$. Given the optimal set of prices,

$$
D_{1}\left(S, P^{*}\right)=\frac{\theta^{+}}{2} \text {. }
$$

Hence the profit maximizing strategy is to meet demand with a unique retail product on the market. As profits for a single-product monopolist are increasing in the quality of the product supplied, it follows that the monopolist will supply quality $S_{r}^{*}=S^{+}$and price accordingly.

It is never optimal for the incumbent to introduce lower quality products on the market, and this follows from two countervailing effects. On the one hand, there is a market expansion effect. Introducing a lower quality product (at a lower price) increases market coverage. Some consumers that would otherwise not purchase demand the new product, and this increases the incumbent's profits. On the other hand, there is a product substitution effect. A share of consumers that would otherwise purchase the higher quality product switches to the new one. This reduces profits due to the lower price of the new product. The second effect always prevails over the first, so the risk of cannibalization between products ensures the incumbent does not introduce lower qualities in the market. The result is driven by the assumptions made on the demand side, which ensure 
that the product substitution effect prevails whenever several products are supplied on the market. More generally, the tradeoff between both effects will depend on consumers' utility function and the distribution of consumers' valuation for quality. I discuss the impact of alternative demand specifications on the results in Section 5.

\subsection{Open access under functional separation}

I next analyze the market under functional separation. The incumbent's upstream and downstream operations are two separate and independent business units, each maximizing their own returns. I will refer to them as the wholesale and the retail division, respectively.

The wholesale division manages the incumbent's infrastructure and provides service to all operators in the wholesale market, including the incumbent's retail division and all entrants. The retail division interacts with the wholesale division on the same terms and conditions as entrants. This implies equivalence of input; a common interface between infrastructure operations and all downstream firms. Quality of service is infrastructure dependent and controlled by the wholesale division, so operators cannot improve upon the quality of service supplied in the wholesale market. Wholesale prices are subject to a price cap $\bar{p}$ determined by the regulator, and I assume $\bar{p}$ is below the monopoly price derived in the previous section.

Retail prices are unregulated. The retail division services the incumbent's downstream customers and controls its retail pricing. Entrants quote their retail prices independently. The next proposition characterizes the equilibrium.

Proposition 1. Under functional separation, the incumbent's wholesale division supplies maximum quality to all operators present in the market. The market outcome is characterized by

$$
S_{w}^{*}=S^{+} \quad \text { and } \quad p_{w}^{*}=\bar{p},
$$

and positive profits are derived only by the incumbent's wholesale division,

$$
\pi_{\text {separation }}^{*}=\bar{p}\left(\theta^{+}-\frac{\bar{p}}{S^{+}}\right) .
$$

Proof. Consider the wholesale division's problem. Several qualities can be supplied on the wholesale market, but only prices below or equal to $\bar{p}$ can be charged for all qualities. I next argue that it is optimal to supply a unique quality at a single price to all operators and characterize the market outcome.

First, it is not profitable to supply a given quality to only one operator. If a given quality is supplied at price $p_{w} \leq \bar{p}$ to several operators, price competition ensures the retail price for that quality will be $p_{w}$. This follows from the fact that products from these operators are perfect substitutes for consumers, so price competition drives their prices down to marginal cost, $p_{w}$. If 
a given quality is supplied to only one operator, this operator will offer a differentiated product in the downstream market and could price above $p_{w}$. But this can never be profitable for the wholesale division as only $p_{w}$ can be appropriated from sales, and higher retail prices leading to lost sales result in lower profits. Thus the wholesale division cannot profit from supplying a given quality to only one operator.

Second, it is not profitable to price-discriminate operators for a given quality. If a given quality is supplied to several operators at different prices, those operators enjoying lower prices can undercut others at retail. Thus operators facing higher wholesale prices will face no demand. Hence it is optimal for the wholesale division to quote a unique price for each wholesale quality supplied, and to supply each quality to several operators.

Third, it is not profitable to supply more than one quality on the wholesale market. Consider the case in which $N$ qualities are introduced in the wholesale market. If qualities are ordered in decreasing sequence, $S_{1}>S_{2}>\ldots>S_{N}$, wholesale prices for these qualities must satisfy $\bar{p} \geq p_{1}>p_{2}>\ldots>p_{N}$ for all qualities to face demand at retail. As the wholesale division fully appropriates the revenues from all qualities, this problem is equivalent to the monopolist's problem implied by Lemma 1 under the constraint that $p_{1} \leq \bar{p}$. It follows from the solution to the monopolist's problem, which is independent of $p_{1}$, that the wholesale division will introduce a unique quality on the market. And since the wholesale price cap is below the monopoly price, $\bar{p}<p_{r}^{*}$, the wholesale division will quote price $p_{w}^{*}=\bar{p}$ and supply only maximum quality to all operators, $S_{w}^{*}=S^{+}$.

Under functional separation, the incumbent's wholesale division has incentives to supply only the maximum quality of service available. As a result, quality of service is homogeneous across all operators in the market, including the incumbent's own retail division. The result shows that effective functional separation, where the incumbent's retail division interacts with the wholesale division on the same terms as entrants, provides incentives for the wholesale division to increase both the substitutability of downstream products and market coverage. Thus functional separation not only ensures there are no incentives to discriminate across operators, but generates incentives for the wholesale division to homogenize wholesale quality of service.

The problem of the wholesale division can be characterized as follows. On the one hand, profits generated at retail are lost to downstream firms, as only wholesale prices can be appropriated from sales. Hence the wholesale division's strategy must minimize downstream profits, which in turn can be accomplished by supplying the same quality to all operators at a common wholesale price. This strengthens price competition between operators, as they are perceived as perfect substitutes by consumers, driving downstream prices down to the wholesale price. On the other hand, given that the wholesale price is constrained by the price cap imposed by the regulator, the wholesale division needs to maximize market coverage in order to maximize profits. This in turn is accomplished by supplying only the maximum quality on the market. As a result, the incumbent's total profits 
across both divisions are lower than those obtained under monopoly, due to both the wholesale price cap and the lower retail prices driven by downstream competition.

\subsection{Open access under wholesale regulation}

I next consider the case of an open access regime based on wholesale regulation. The incumbent is vertically integrated and supplies infrastructure services to entrants through a regulated wholesale market. This is the most widespread market configuration under open access regimes, and has generally preceded functional separation in the countries that have implemented it.

The incumbent maximizes profits over two sources of revenue: wholesale products supplied to entrants in the upstream market and retail products supplied to consumers in the downstream market. Wholesale qualities are infrastructure dependent and controlled by the incumbent. There is a price cap $\bar{p}$ in the wholesale market determined by the regulator, and retail prices are unregulated. I assume $\bar{p}$ is below the monopoly price. The following proposition summarizes the findings.

Proposition 2. Under wholesale regulation, the incumbent offers a retail product of maximum quality,

$$
S_{r}^{*}=S^{+} \quad \text { and } \quad p_{r}^{*}=\bar{p}+\frac{\theta^{+}\left(S^{+}-S_{w}\right)}{2},
$$

and profits from supplying a single and degraded wholesale quality to entrants,

$$
\pi_{\text {wholesale }}= \begin{cases}\pi_{\text {monopoly }}^{*} & \text { if } S_{w} \leq 2 \bar{p} / \theta^{+} \\ \bar{p}\left(\theta^{+}-\frac{\bar{p}}{S_{w}}\right)+\frac{\left(S^{+}-S_{w}\right)}{4} \theta^{+^{2}} & \text { if } 2 \bar{p} / \theta^{+}<S_{w}<S^{+} \\ \pi_{\text {separation }}^{*} & \text { if } S_{w}=S^{+} .\end{cases}
$$

Proof. Consider the incumbent's problem. At least one wholesale quality must be supplied to entrants. It follows from the proof of Proposition 1 that it is optimal to supply any given wholesale quality to several entrants at a common price. I proceed by assuming that the incumbent offers a unique wholesale quality $S_{w}$ at price $p_{w}$ and a unique retail quality $S_{r}$ at prices $p_{r}$. Downstream price competition ensures the retail price quoted by entrants matches the wholesale price $p_{w}$. I will show that introducing additional qualities is not profitable.

Consider the case in which a superior quality is supplied on the retail product, $S_{r}>S_{w}$. The incumbent's profits are then given by

$$
\begin{aligned}
\pi_{w h o l e s a l e}\left(S_{r}, S_{w}, p_{r}, p_{w}\right) & =D_{r}\left(S_{r}, S_{w}, p_{r}, p_{w}\right) p_{r}+D_{w}\left(S_{r}, S_{w}, p_{r}, p_{w}\right) p_{w} \\
& =\left(\theta^{+}-\frac{p_{r}-p_{w}}{S_{r}-S_{w}}\right) p_{r}+\left(\frac{p_{r}-p_{w}}{S_{r}-S_{w}}-\frac{p_{w}}{S_{w}}\right) p_{w} .
\end{aligned}
$$

The first order condition of this expression with respect to $p_{r}$ yields the optimal pricing for the 
retail product,

$$
p_{r}^{*}=p_{w}+\frac{\theta^{+}\left(S_{r}-S_{w}\right)}{2},
$$

and substituting the optimal price in (7) obtains

$$
\pi_{w h o l e s a l e}\left(S_{r}, S_{w}, p_{r}^{*}, p_{w}\right)=p_{w}\left(\theta^{+}-\frac{p_{w}}{S_{w}}\right)+\frac{\left(S_{r}-S_{w}\right)}{4} \theta^{+^{2}}
$$

The first order condition with respect to $p_{w}$ yields

$$
p_{w}^{*}=\frac{\theta^{+} S_{w}}{2}
$$

A wholesale price equal or above $p_{w}^{*}$ ensures entrants face no demand, $D_{w}=0$. However, optimal pricing may be unfeasible depending on wholesale quality $S_{w}$, as the incumbent is price constrained in the wholesale market and it may be the case that $p_{w}^{*}>\bar{p}$. So in the presence of a price cap, wholesale pricing alone cannot ensure $D_{w}=0$.

As profits in (9) are strictly increasing in the quality of the retail product,

$$
S_{r}^{*}=S^{+}
$$

The profit-maximizing quality for the wholesale product can be obtained from the first order condition of (9) with respect to $S_{w}$, which yields a unique positive solution

$$
S_{w}^{*}=\frac{2 p_{w}}{\theta^{+}}
$$

With a wholesale quality below or equal to $S_{w}^{*}$, entrants face no demand, $D_{w}=0$. For all feasible wholesale prices, it can easily be shown that profits in (9) are strictly decreasing in wholesale quality in the range $S_{w} \in\left[\frac{2 p_{w}}{\theta^{+}}, S^{+}\right]$, with a minimum at $S_{w}=S^{+}$.

The previous result implies that supplying two qualities on the market such that $S_{r}>S_{w}$ is the profit maximizing solution for the incumbent. First, profits would be lower supplying a higher quality on the wholesale product, $S_{w}>S_{r}$, as in this case the price cap constrains the incumbent from optimally pricing the wholesale product given (8). Second, (11) implies that it is not profitable to introduce more qualities on the market. Thus the incumbent will always supply maximum quality at retail and degrade the wholesale quality supplied to entrants to the point they face no demand, or to the largest extent possible.

When open access is implemented under wholesale regulation and the incumbent is vertically integrated, non-cost-raising discrimination is always profitable irrespectively of access prices and the number of competitors. The incumbent has incentives to differentiate her retail product by degrading the wholesale quality supplied to competitors. By offering a superior product to consumers the incumbent can soften competition and sustain higher retail prices, thereby extracting 
higher surplus from consumers with the highest willingness to pay, those who most value quality.

The incumbent's profits are strictly increasing in the degree of quality discrimination, and the profit maximizing solution implies degrading the quality supplied to competing operators to the extent that they face no demand. This can be achieved with a wholesale quality that is valuable to consumers as a standalone product on the marketplace, yet dominated by the incumbent's retail product. Thus the wholesale market is open to competitors, but the wholesale input is of such inferior quality that it precludes them from gaining market share. As a result, the market is foreclosed and the incumbent achieves monopoly rents. Whenever such degree of discrimination is unfeasible, the incumbent will choose to engage in discrimination to the largest extent possible.

Quality is an effective foreclosure tool for the incumbent under wholesale regulation. The impact of quality discrimination is similar to that of a price squeeze, a foreclosure tactic based on raising the access price faced by competitors. If the incumbent were not subject to a wholesale price cap, she could alternatively implement the monopoly solution by raising wholesale prices. ${ }^{14}$ Hence wholesale prices and quality of service are substitutable tools for the incumbent, and price regulation alone is insufficient to preclude market foreclosure when non-cost-raising discrimination is feasible. It should also be noted that retail-minus schemes tying the incumbent's retail and wholesale prices, as implemented in some open access regimes, would not alter this result since quality discrimination allows the incumbent to bypass price constraints.

The result strengthens the case for foreclosure in regulated industries. The cost-raising discrimination literature has mostly assumed that discrimination does not reduce consumers' willingness to pay for the products of competitors but instead increases their operating costs. Under that form of discrimination, Sibley and Weisman [22], Weisman and Kang [25], Beard, Kaserman and Mayo [3], and Mandy and Sappington [16] find that high access prices or the intensity of downstream competition can reduce the incumbent's incentives to discriminate. The result presented here suggests that non-cost-raising discrimination is a more general phenomenon.

Mandy and Sappington [16] also consider a form of demand-reducing discrimination with Bertrand competition downstream. In their model, demand-reducing discrimination is a mechanism that shifts inwards the demand of competitors, and this intensifies retail price competition reducing the incumbent's downstream profits. They conclude that the incumbent has no incentives to engage in demand-reducing discrimination. In contrast, the discrimination mechanism considered here impacts the product quality of competitors, and this reduces their demand but also expands that of the incumbent whose quality remains unaffected. The increase in the quality gap between both products (or their effective differentiation) softens retail price competition and increases the incumbent's downstream profits, and this effect offsets upstream revenues ensuring that discrimination remains profitable.

\footnotetext{
${ }^{14}$ Even if subject to a price cap, the incumbent could potentially implement the monopoly solution with a twopart tariff. The optimal tariff would respect the per-unit price cap but would impose a lump-slump transfer on competitors.
} 


\section{Social welfare analysis}

I next compare social welfare under the three market configurations.

Proposition 3. Social welfare is highest under functional separation, followed by wholesale regulation, and lowest under monopoly. Quality discrimination strictly decreases social welfare.

Proof. The proof is included in the Appendix.

The key factor driving the ranking is the degree of discrimination engaged by the incumbent. The stronger the degree of discrimination, the lower the intensity of competition in the downstream market, which in turn increases the incumbent's profits but reduces consumer surplus. Discrimination harms consumers with high valuation for quality the most, due to the higher prices it imposes on high quality products. Discrimination also harms consumers with low valuation for quality by driving them out of the market, reducing market coverage.

Market coverage increases in the model are driven by consumers with low quality valuations choosing to purchase as higher quality products become available at low prices. This is consistent with the fact that both prices as well as terms of service have been identified as the main barriers to broadband adoption for low-income consumers. ${ }^{15}$ All consumers in the model are assumed to have access to broadband services on equal terms, so geographical coverage of the incumbent's infrastructure is not a limiting factor in the analysis. This is a reasonable assumption for the majority of the consumer population in developed countries, but will generally not hold in sparsely populated areas or developing countries. ${ }^{16}$

The source of inefficiency identified in the model is the regulator's inability to deter discrimination under wholesale regulation. If the regulator can detect and punish discrimination to some extent, then discrimination will become costly for the incumbent and this will reduce the degree of discrimination incurred, increasing social welfare. ${ }^{17}$ Under functional separation, other important sources of social welfare not captured in the model are the costs of implementing separation, as well as the efficiency gains lost with the vertical disintegration of the incumbent. These dimensions of the problem are further discussed in the next section.

\footnotetext{
${ }^{15}$ See the Social Science Research Council's report commissioned by the FCC: 'Broadband Adoption in LowIncome Communities,' March 2010.

${ }^{16}$ See Faulhaber and Hogendorn [10] for an analysis of infrastructure coverage in a competitive environment.

${ }^{17}$ From a regulatory standpoint, an advantage of functional separation is that it can significantly facilitate monitoring. This is still critical under functional separation. For instance, if side-transfers were allowed in the model between the wholesale division and downstream operators under separation (in addition to any access price charges), the wholesale division would profit from colluding with one operator and discriminating against the remaining. If the incumbent's divisions operate under joint ownership, the benefits of collusion between these divisions could be appropriated without the need for transfers. This would necessarily reduce the profits of the wholesale division, however, which underscores the regulatory importance of carefully designing the incentives under which the wholesale division is run.
} 


\section{$5 \quad$ Extensions to the model}

The results presented above rely on several simplifications that merit further discussion. The incumbent's production technology is characterized by a zero cost structure, engaging in discrimination is assumed to be costless, demand specification is linear, and the impact of the incumbent's vertical integration is not incorporated in the model. I next review these assumptions and consider how they may impact the findings. Although the basic model specification may appear restrictive, the review suggests that non-cost-raising discrimination is a general phenomenon under richer vertical differentiation frameworks. The review also suggests that open access regimes can reduce quality of service thresholds in the market, an effect which is not captured in the basic model. The effect is intensified under functional separation, where it can drive quality of service homogenization depending on demand-side factors, price cap levels, and the intensity of the scope economies lost with the incumbent's vertical disintegration. ${ }^{18}$

Production costs. The results on quality discrimination are qualitatively robust to the presence of production costs in the model. A fixed infrastructure cost, for example, does not affect the quality-wise strategy of the incumbent. Quality-dependent fixed costs are of more interest, and I next discuss the most simple and tractable case. Consider an incumbent facing an infrastructure cost $c\left(S^{+}\right)$to supply on the market qualities within the range $S \in\left[0, S^{+}\right]$, where $c$ is increasing and convex in $S^{+}$, that is $c^{\prime}\left(S^{+}\right)>0$ and $c^{\prime \prime}\left(S^{+}\right)>0$. Thus an infrastructure capable of meeting higher quality thresholds commands increasing investments. Note that the maximum quality threshold $S^{+}$becomes endogenous in this setting.

With quality-dependent fixed costs, the incumbent will take into account the infrastructure cost when deciding what qualities to serve on the market. The incumbent will choose the infrastructure costs to incur by equating the marginal cost of a quality increase with the marginal revenue of supplying it. Yet as long as degrading the quality supplied to competitors increases revenues but does not incur additional costs, the qualitative results on quality discrimination continue to hold. The intuition conveyed here is that degrading quality, rather than increasing it, does not require infrastructure improvements. The maximum quality available in the market, however, will now vary with the market configuration. It can be shown that the quality supplied in the market is lower under functional separation than under monopoly, as lower retail prices reduce the marginal revenue of quality. Under wholesale regulation, the incumbent's retail quality will fall between the two previous cases, and is increasing in the degree of discrimination.

Richer cost structures such as quality-dependent variable costs, which increase with both quality and market coverage, unfortunately render the problem intractable when introducing a wholesale market. Complex trade-offs arise under wholesale regulation as quality discrimination decreases

\footnotetext{
${ }^{18}$ The existence of such an effect merits further empirical analysis, although initial reports from Ofcom in the UK suggest that the initial impact of separation on quality of service thresholds is unlikely to be significant. See Ofcom's consultation 'A New Pricing Framework for Openreach,' May 2009.
} 
the quality cost component but increases the market coverage component.

Discrimination costs. The basic model assumes that it is not costly for the incumbent to discriminate against competing operators by degrading the quality of service supplied to them. However, if the incumbent faces the risk of being detected and punished by the regulator, it will anticipate a cost $c_{d}$ of engaging in discrimination. Denote the degree of discrimination under wholesale regulation by $\hat{S}=S_{r}-S_{w}$ (over the relevant range for $S_{w}$ where there is positive demand for wholesale products). Because both the probability of detection and the punishment will increase with the degree of discrimination incurred, the expected cost of discrimination will satisfy $c_{d}(\hat{S}=0)=0$ and are increasing and convex, $c_{d}^{\prime}(\hat{S})>0$ and $c_{d}^{\prime \prime}(\hat{S})>0$.

An incumbent anticipating discrimination costs will choose a degree of discrimination $\hat{S}$ to maximize profits, by accounting both for the costs and the revenues derived from discrimination. The revenues of discrimination are described by wholesale profits in (9) and can be written as $\pi_{d}(\hat{S})=\pi_{\text {wholesale }}\left(S^{+}, S^{+}-\hat{S}, p_{r}^{*}, \bar{p}\right)-\pi_{\text {wholesale }}\left(S^{+}, S^{+}, \bar{p}, \bar{p}\right)$. It follows that $\pi_{d}(\hat{S}=0)=0$, and is increasing and concave, $\pi_{d}^{\prime}(\hat{S})>0$ and $\pi_{d}^{\prime \prime}(\hat{S})<0$. Two scenarios are possible. If the regulator has a high detection rate and punishments are severe, that is $c_{d}(\hat{S})$ increases steeply so that $c_{d}(\hat{S})>\pi_{d}(\hat{S})$ for all $\hat{S}$, discrimination will never pay off. Otherwise, if discrimination costs do not increase steeply so that $c_{d}(\hat{S})<\pi_{d}(\hat{S})$ for some range of $\hat{S}$, a positive degree of discrimination will continue to hold. Therefore, as long as there is some threshold of discrimination which is undetectable by the regulator, discrimination costs will reduce the degree of discrimination incurred by the incumbent but are unlikely to completely deter discrimination.

Alternative demand specifications. The analysis assumes an explicit functional form for consumer preferences and a uniform distribution of consumer valuations for quality. As discussed in Lemma 1, this specification ensures the monopoly solution is based on a pooling menu, that is, on serving a unique quality on the market. This setting allows for the analysis to be focused on quality discrimination strategies while abstracting from complex product ranges. Alternative model specifications could drive a monopolist to supply a separating menu by offering multiple products targeted at different consumer segments. Such specifications include consumer utility functions with non-linear components for quality and non-uniform distributions of quality valuation in the consumer population. Sappington [19] provides a discussion of the multi-product monopolist, and Acharyya [1] analyzes the existence of separating and pooling equilibria within the family of models close to the one considered here.

The analysis of quality discrimination becomes more complex when the monopoly solution implies a separating menu with several product qualities. If quality is costless, such a menu will include the maximum quality $S^{+}$and one or more lower qualities. Proposition 1 shows that it is optimal for the incumbent to supply wholesale qualities to several operators at a common price in order to limit their downstream market power, and this result relies only on the consumer utility function being increasing in quality. Based on this property, I next discuss the incumbent's 
problem when a separating menu is optimal.

Under wholesale regulation, the incumbent can implement the separating menu by supplying through the wholesale market any qualities priced below the price cap in the monopoly solution (and pricing them according to the monopoly solution). Qualities priced above the price cap can only be optimally supplied at retail. If the price cap is so low that no qualities in the separating menu are priced within its range, it is optimal for the incumbent to degrade the wholesale quality and ensure it faces no demand. This outcome is equivalent to full discrimination in the pooling menu analysis, where the wholesale product faces no demand. If full discrimination is unfeasible, the incumbent will attain a second-best with an alternative pooling or separating menu that approximates the monopoly solution. The latter implies substituting the lowest quality product on the monopoly menu with an even lower wholesale quality priced exactly at the price cap.

Under functional separation, the wholesale division cannot price qualities above the price cap, so the constraint is stronger than under wholesale regulation. Again, a second-best solution will imply a pooling menu or an alternative separating menu, with the latter exhibiting lower prices and qualities with respect to the low quality products on the monopoly menu. The stronger constraint implies that the pooling menu solution is also more attractive under functional separation compared to wholesale regulation.

Vertical integration economies. The potential efficiency gains lost with the functional separation of the incumbent are a main objection to structural intervention. Incumbent telecommunications operators have opposed all forms of separation by warning against the upfront costs of implementation and their negative operational impact. From a technical standpoint, and although most observers agree to the existence of vertical integration economies in the telecommunications sector, few instances of the literature have analyzed their impact. Sappington [20] and Bustos and Galetovic [5] consider cost-raising discrimination in the presence of scope economies, which allow an integrated incumbent to sustain lower costs than a separated incumbent. Such gains may originate, for instance, from improved coordination of infrastructure and retail operations. They identify a trade-off between the efficiency gains generated by scope economies and the degree of discrimination incurred by the incumbent. Under vertical integration, the trade-off arises because scope economies drive the regulator to set lower access prices, which in turn increases the incentives of the incumbent to discriminate in order to appropriate the larger consumer surplus generated. Both papers find that, as long as scope economies are not too strong, separation yields higher consumer surplus due to reduced discrimination.

A similar result arises in my model. Although I haven't modeled the interplay between the incumbent's production costs and the price cap set by the regulator, note that the revenues of discrimination $\pi_{d}(\hat{S})$ described above are decreasing in the price cap $\bar{p}$. Thus any reduction in the regulated wholesale price under vertical integration will increase the incumbent's incentives to discriminate, and this will reduce consumer surplus unless discrimination costs are sufficiently 
steep.

Other potential benefits of vertical integration not addressed in the discrimination literature may accrue to the product space. Within an integrated firm, the interplay of infrastructure management and knowledge of consumer demand may facilitate product innovation and quality of service improvements. Quality of service under functional separation could be reduced if the infrastructure division is simply unable to match the performance of an integrated firm. If separation increases the costs required to meet quality of service thresholds, for instance if the incumbent faces qualitydependent fixed costs and separation expands the cost curve $c\left(S^{+}\right)$, then vertical disintegration will reduce the quality supplied in the market.

Integration may facilitate some degree of horizontal differentiation by enabling the incumbent to differentiate her retail products with respect to those supplied over wholesale access. The incumbent's scope to do so is presumably larger than under functional separation with a wholesale division subject to equivalence of input requirements. A positive degree of horizontal differentiation softens the intensity of downstream competition, and this alters the comparative profitability of the downstream and upstream markets for the incumbent. If downstream competition is softened in this way, the upstream market becomes more attractive and this reduces the degree of discrimination incurred under integration.

Vertical integration also exhibits regulatory disadvantages. The incumbent's integration difficults external monitoring and this reduces the regulator's ability to detect discrimination. Furthermore, some of the gains derived from vertical integration may not be independent of the regulatory context firms operate in. In a deregulated marketplace, some of the gains of integration may be driven by asset specificity and incomplete contracts. If infrastructure operations and retail operations were to independently contract in an open market, the mutual dependence of both parties is prone to generate conflicts over the revenue stream they jointly generate. Under functional separation, regulatory intermediation can mitigate this problem and reduce uncertainty, in turn reducing the costs incurred by the parties.

\section{Discussion}

Vertically integrated telecommunications operators under open access regulation have strong incentives to degrade wholesale quality. The findings presented here strengthen the case for discrimination previously identified in the cost-raising discrimination literature. Under the wholesale regulation frameworks present in most countries, and given the empirical evidence from the UK market, there is reason to suspect that discrimination may be a widespread phenomenon. An immediate policy implication of the above is that monitoring efforts should analyze the extent of the problem by constructing quality of service indexes that explicitly test for discrimination, such as those pursued by Ofcom in the UK.

The results cast doubt on the effectiveness of wholesale regulation to deliver the full scope 
of benefits expected from an open access regime, such as increased broadband penetration and lower retail prices for high quality of service tiers. Functional separation has desirable properties to deliver these goals, by better aligning the infrastructure provider's incentives with those of consumers. I should stress, however, that these results rely on effective separation that yields an equal playing field for all operators. This may require physical and administrative separation of the incumbent's wholesale division, management bonuses to be designed accordingly, and equivalence of input requirements for wholesale operations. Effective separation also entails costs beyond those of upfront implementation. Separation sacrifices the efficiency gains derived from the vertical integration of the incumbent, and this may lead to increased infrastructure costs, lower quality of service thresholds, or reduce the scope for downstream product differentiation.

But the main lesson from the model is that one cannot have it all under open access, integration and no discrimination. And the true extent of the downsides outlined above is an empirical question for which we may yet lack a proper answer. The implementation of functional separation in several countries over recent years provides an opportunity for further research in this area. How does functional separation impact infrastructure costs and the quality and variety of broadband products in the countries that have implemented it? Initial evidence from the UK is widely regarded as positive. Ofcom reports lower broadband prices, increased consumer switching and product variety, and increased broadband penetration with more areas serviced by entrants. ${ }^{19}$ The UK has also improved its position in the global rankings of broadband performance in the years that have followed the implementation of functional separation, and the European Union has recognized separation as a useful tool that should be considered by Member States where wholesale regulation has failed to foster competition.

Functional separation may also reduce the incentives for private investment in infrastructure, which holds important implications for the deployment of next-generation networks. If the revenues derived from infrastructure ownership are reduced, an effect of open access regimes which is intensified under separation, incentives to invest in infrastructure will also decrease. Several papers have formalized this argument. ${ }^{20}$ But the empirical evidence so far is inconclusive. The Berkman report [9], perhaps the most extensive study on the performance of the broadband sector across countries, finds that infrastructure investment has flourished in several countries following the implementation of open access regimes. This is the case of Japan, Sweden, France, and the Netherlands, among others. Functional separation has also been adopted as a model for the deployment of new infrastructure. Both on a small scale in cities such as Amsterdam, which created a public and private partnership to wire 40,000 of its buildings with optic fiber, and on a much larger scale, with Australia pioneering the construction of a national broadband network to be

\footnotetext{
${ }^{19}$ See Ofcom's 'Impact of the Strategic Review of Telecoms,' May 2009. Ofcom identifies functional separation together with reductions in regulated access prices as the main drivers of retail broadband competition in the UK. See also Ofcom's 'Communications Market Report,' August 2011.

${ }^{20}$ See for instance Bourreau and Dogan [4], Foros [11], and Kotakorpi [15], which show that open access regimes can reduce the incumbent's investment incentives or delay investment in time.
} 
managed under an open access regime enforcing separation.

The social welfare implications of broadband regulation extend beyond those captured in the model. Broadband is increasingly recognized as critical contributor to economic competitiveness and growth, exhibiting positive externalities on other sectors of the economy. Policy innovation informed by technical analysis and comparative performance evaluations across countries should play an important role in the regulatory debate. Otherwise society may not only pay a high price to the incumbent, but also a high opportunity cost in lost productivity gains.

\section{Appendix}

Proof of Proposition 3. Consider social welfare in the monopoly solution. Given the monopoly price and quality in Lemma 1, market coverage is given by

$$
\theta_{i} \in\left(\frac{\theta^{+}}{2}, \theta^{+}\right]
$$

As consumers purchase quality $S^{+}$at price $p_{m}^{*}$, consumer welfare is

$$
\begin{aligned}
C W_{\text {monopoly }} & =\int_{\frac{\theta^{+}}{2}}^{\theta^{+}}\left(\theta_{i} S^{+}-p_{m}^{*}\right) d \theta_{i} \\
& =\frac{1}{8} S^{+} \theta^{+^{2}} .
\end{aligned}
$$

Producer welfare is given by the incumbent's profits

$$
\begin{aligned}
P W_{\text {monopoly }} & =\left(\theta^{+}-\frac{\theta^{+}}{2}\right) p_{m}^{*} \\
& =\frac{1}{4} S^{+} \theta^{+^{2}} .
\end{aligned}
$$

We can now write social welfare under monopoly

$$
S W_{\text {monopoly }}=C W_{\text {monopoly }}+P W_{\text {monopoly }}=\frac{3}{8} S^{+} \theta^{+^{2}}
$$

Consider next the case of functional separation. Given the solution from Proposition 1, market coverage is

$$
\theta_{i} \in\left(\frac{\bar{p}}{S^{+}}, \theta^{+}\right]
$$


Consumers purchase quality $S^{+}$at price $\bar{p}$, so consumer welfare is

$$
\begin{aligned}
C W_{\text {separation }} & =\int_{\frac{\bar{p}}{S^{+}}}^{\theta^{+}}\left(\theta_{i} S^{+}-\bar{p}\right) d \theta_{i} \\
& =\frac{\left(\bar{p}-S^{+} \theta^{+}\right)^{2}}{2 S^{+}}
\end{aligned}
$$

and producer welfare is given by the wholesale division's profits as operators obtain no profits in the downstream market,

$$
P W_{\text {separation }}=\left(\theta^{+}-\frac{\bar{p}}{S^{+}}\right) \bar{p} .
$$

Hence social welfare under functional separation is then

$$
S W_{\text {separation }}=C W_{\text {separation }}+P W_{\text {separation }}=\frac{1}{2}\left(S^{+} \theta^{+^{2}}-\frac{\bar{p}^{2}}{S^{+}}\right) .
$$

Finally, consider the case of wholesale regulation. Under imperfect discrimination, both the retail and the wholesale products face demand in the downstream market given qualities $S^{+}, S_{w}$ and prices $p_{r}^{*}, p_{w}$. Consumers demanding the retail and the wholesale product are given by

$$
\theta_{i}^{r} \in\left(\frac{\theta^{+}}{2}, \theta^{+}\right] \quad \text { and } \quad \theta_{i}^{w} \in\left(\frac{p_{w}}{S_{w}}, \frac{\theta^{+}}{2}\right]
$$

respectively, so consumer welfare is

$$
\begin{aligned}
C W_{\text {wholesale }} & =\int_{\frac{\theta^{+}}{2}}^{\theta^{+}}\left(\theta_{i} S^{+}-p_{r}^{*}\right) d \theta_{i}+\int_{\frac{p_{w}}{S_{w}}}^{\frac{\theta^{+}}{2}}\left(\theta_{i} S_{w}-p_{w}\right) d \theta_{i} \\
& =\frac{3 S_{w}+S^{+}}{8} \theta^{+^{2}}-p_{w} \theta^{+}+\frac{p_{w}^{2}}{2 S_{w}} .
\end{aligned}
$$

Entrants obtain no profits in equilibrium, so producer welfare is given by the incumbent's profits,

$$
\begin{aligned}
P W_{\text {wholesale }} & =\left(\theta^{+}-\frac{\theta^{+}}{2}\right) p_{r}^{*}+\left(\frac{\theta^{+}}{2}-\frac{p_{w}}{S_{w}}\right) p_{w} \\
& =\frac{S^{+}-S_{w}}{4} \theta^{+^{2}}+p_{w} \theta^{+}-\frac{p_{w}^{2}}{S_{w}}
\end{aligned}
$$

Hence social welfare is

$$
S W_{\text {wholesale }}=C W_{\text {wholesale }}+P W_{\text {wholesale }}=\frac{S_{w}+3 S^{+}}{8} \theta^{+^{2}}-\frac{p_{w}^{2}}{2 S_{w}} .
$$

Taking into account that $S_{w}^{*}<S_{w}<S^{+}$, and that $p_{w}<p_{w}^{*}$ and $p_{w} \leq \bar{p}$, it follows that $S W_{\text {separation }}>S W_{\text {wholesale }}>S W_{\text {monopoly }}$. 


\section{References}

[1] Acharyya, Rajat (1998), 'Monopoly and product quality. Separating or pooling menu?,' Economics letters 61 187-194.

[2] Armstrong, Mark and David E. M. Sappington (2007), 'Recent Developments in the Theory of Regulation,' in Mark Armstrong and Rob Porter (Eds), Handbook of Industrial Organization, Volume III, North Holland.

[3] Beard, T. Randolph, David L. Kaserman, John W. Mayo (2001), 'Regulation, vertical integration and sabotage,' Journal of Industrial Economics 49 (3) 319-333.

[4] Bourreau, Marc and Pinar Dogan (2005), 'Unbundling the local loop,' European Economic Review 49 173-199.

[5] Bustos, Alvaro E. and Alexander Galetovic (2009), 'Vertical Integration and Sabotage with a Regulated Bottleneck Monopoly,' B.E. Journal of Economic \& Policy 9 (1) 35 .

[6] Champsaur, Paul and Jean-Charles Rochet (1989), 'Multiproduct Duopolists,' Econometrica 57 (3) 533-557.

[7] Dixit, Avinash (1979), 'Quality and Quantity competition,' Review of Economic Studies 46 (4) 587-599.

[8] Economides, Nicholas (1998), 'The incentive for non-price discrimination by an input monopolist,' International Journal of Industrial Organization 16 271-284.

[9] Faris, Robert, Urs Gasser, Laura Miyakawa and Stephen Schultze (2010), 'Next Generation Connectivity: A review of broadband Internet transitions and policy from around the world,' Berkman Center for Internet \& Society report, Harvard University.

[10] Faulhaber, Gerald R. and Christiaan Hogendorn (2000), 'The market structure of broadband telecommunications,' Journal of Industrial Economics 48 (3) 305-329.

[11] Foros, Øystein (2004), 'Strategic investments with spillovers, vertical integration and foreclosure in the broadband access market,' International Journal of Industrial Organization 22 1-24.

[12] Gabszewicz, Jean Jaskold and Jacques François Thisse, J.F. (1979), 'Price Competition, Quality and Income Disparities,' Journal of Economic Theory 20 340-359.

[13] Gal-Or, Esther (1983), 'Quality and Quantity Competition,' Bell Journal of Economics 14 (2) 590-600. 
[14] Katz, Michael L. (1997), 'Ongoing reform of U.S. telecommunications policy,' European Economic Review 41 681-690.

[15] Kotakorpi, Kaisa (2006), 'Access price regulation, investment and entry in telecommunications,' International Journal of Industrial Organization 24 1013-1020.

[16] Mandy, David M. and David E. M. Sappington (2007), 'Incentives for sabotage in vertically related industries,' Journal of Regulatory Economics 31 235-260.

[17] Mussa, Michael and Sherwin Rosen (1978), 'Monopoly and Product Quality,' Journal of Economic Theory 18 301-317.

[18] Rubinfeld, Daniel L. and Hal J. Singer (2001), 'Vertical foreclosure in broadband access?,' Journal of Industrial Economics 49 (3) 299-318.

[19] Sappington, David E. M. (2005), 'Regulating Service Quality: A Survey,' Journal of Regulatory Economics 27 (2) 123-154.

[20] Sappington, David E. M. (2006), 'On the merits of Vertical Divestiture,' Review of Industrial Organization 29 171-191.

[21] Shaked, Avner and John Sutton (1982), 'Relaxing Price Competition Through Product Differentiation,' Review of Economic Studies 49 3-13.

[22] Sibley, David S. and Dennis L. Weisman (1998), 'Raising rivals' costs: The entry of an upstream monopolist into downstream markets,' Information Economics and Policy 10 451-470.

[23] Tirole, Jean (1988), 'The Theory of Industrial Organization,' MIT Press, Cambridge, MA.

[24] Wauthy, Xavier (1996), 'Quality choice in models of vertical differentiation,' The Journal of Industrial Economics 64 345-353.

[25] Weisman, Dennis L. and Jaesung Kang (2001), 'Incentives for Discrimination when Upstream Monopolists Participate in Downstream Markets,' Journal of Regulatory Economics 20 (2) 125-139. 